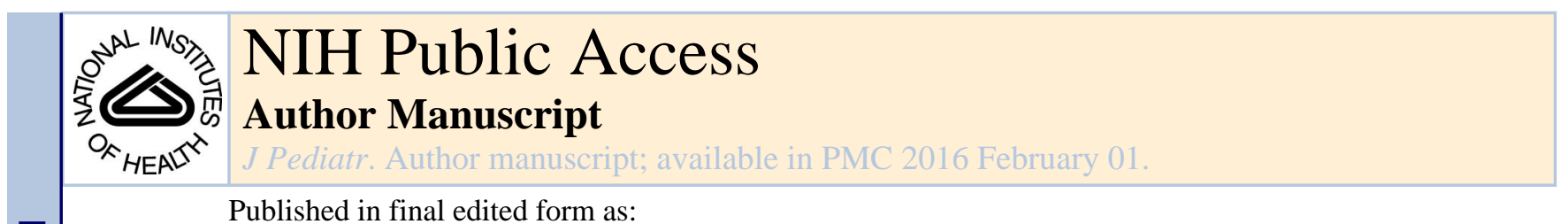

Published in final edited form as:

J Pediatr. 2015 February ; 166(2): 230-233. doi:10.1016/j.jpeds.2014.09.004.

\title{
Plasma asymmetric dimethylarginine levels are increased in neonates with bronchopulmonary dysplasia-associated pulmonary hypertension
}

\author{
Jennifer K. Trittmann ${ }^{1,2,4}$, Eric Peterson ${ }^{4}$, Lynette K. Rogers ${ }^{2,4}$, Bernadette Chen ${ }^{2,4}$, Carl H. \\ Backes $^{2,3,4}$, Mark A. Klebanoff ${ }^{1,4}$, and Leif D. Nelin ${ }^{1,2,4}$ \\ ${ }^{1}$ The Research Institute at Nationwide Children's Hospital \\ ${ }^{2}$ Pulmonary Hypertension Group, Center for Perinatal Research, The Research Institute at \\ Nationwide Children's Hospital \\ ${ }^{3}$ The Heart Center at Nationwide Children's Hospital \\ ${ }^{4}$ Department of Pediatrics, The Ohio State University, Columbus, Ohio, USA
}

\begin{abstract}
Objective-To test the hypothesis that levels of the endogenous inhibitor of NO production, asymmetric dimethylarginine (ADMA), would be greater in preterm infants with bronchopulmonary dysplasia (BPD) -associated pulmonary hypertension $(\mathrm{PH})$ than in infants with BPD alone.
\end{abstract}

Study design-A case control study of 23 patients with both BPD and PH (cases) and 95 patients with BPD but no evidence of PH (controls). Levels of ADMA were compared between cases and controls by $t$-test.

Results-Patients with both BPD and PH have higher plasma levels of ADMA than patients with BPD alone ( $\mathrm{p}=0.04)$. In samples drawn before 28 days of life, higher levels of ADMA were again found in cases compared with controls $(\mathrm{p}=0.02)$. Plasma arginine-to-ADMA ratio was lower in cases than in controls $(\mathrm{p}=0.03)$, suggesting a higher likelihood of inhibition of NO production in patients with both BPD and PH than in patients with BPD alone.

Conclusion-In this neonatal BPD cohort, ADMA levels are elevated in patients with BPD who develop PH. We speculate that ADMA may be both a biomarker and a potential therapeutic target for preterm infants with BPD-associated PH.

(C) 2014 Elsevier Inc. All rights reserved.

Corresponding author: Jennifer K. Trittmann, MD, Center for Perinatal Research, The Research Institute at Nationwide Children's Hospital, 700 Children's Drive, Research Building III, Fifth Floor, Columbus, Ohio 43205, Phone (614) 355-6623, Fax (614) 355-5899, Jennifer.Trittmann@ nationwidechildrens.org.

The authors declare no conflict of interest.

Publisher's Disclaimer: This is a PDF file of an unedited manuscript that has been accepted for publication. As a service to our customers we are providing this early version of the manuscript. The manuscript will undergo copyediting, typesetting, and review of the resulting proof before it is published in its final citable form. Please note that during the production process errors may be discovered which could affect the content, and all legal disclaimers that apply to the journal pertain. 


\section{Keywords}

hypoxia; nitric oxide; nitric oxide synthase; preterm infant

Bronchopulmonary dysplasia (BPD) is the most common pediatric chronic lung disease [1]. Pulmonary hypertension (PH) is a complication of BPD, with a prevalence estimated between 25-37\% [2-4]. PH is associated with an increase in morbidity and mortality [5, 6]. Currently, not only is it difficult to diagnose PH in BPD but there are no clinical tests for predicting which BPD patients will develop PH. PH in BPD is likely the result of abnormal vasculature development in the preterm lung [7]. Both the decreased surface area and vasoconstriction of the pulmonary vasculature can contribute to the increased vascular resistance and higher pulmonary arterial pressures in patients with both BPD and PH.

Nitric oxide (NO) is produced from L-arginine by NO synthase (NOS), and NO is central in maintaining the normal low pulmonary vasculature resistance seen. In patients with certain forms of $\mathrm{PH}$, endogenous NO production is decreased[8-11]. Therefore, the regulation of $\mathrm{NO}$ is potentially both a biomarker and a therapeutic target in BPD-associated $\mathrm{PH}$. The production of NO can be inhibited by asymmetric dimethylarginine (ADMA). Currently, little is known regarding the role of ADMA in neonatal disease.

ADMA is formed by the methylation of arginine residues contained in proteins by the protein arginine methyltransferases (PRMT), and subsequent proteolysis results in the release of methylated arginines including ADMA. ADMA is degraded primarily by dimethylarginine dimethylaminohydrolase (DDAH). ADMA competes with L-arginine for the active site of NOS, and when ADMA is bound to NOS, NO production by NOS is inhibited. Normally, the balance between production of ADMA and its degradation by DDAH results in low levels of ADMA and relatively little inhibition of NOS [12]. However, in cardiovascular and renal disease, levels of ADMA are elevated $[9,13]$. Therefore, we tested the hypothesis that plasma levels of ADMA would be greater in preterm patients with both BPD and PH than in patients with BPD without evidence of PH.

\section{METHODS}

The Institutional Review Board of Nationwide Children's Hospital approved this study with informed consent. All patients admitted to Nationwide Children's Hospital NICUs after September 1, 2009 with the diagnosis of BPD were eligible for this study. BPD was defined according to the NICHD workshop statement as a supplemental oxygen requirement at 28 days of life [14]. Enrollment, clinical data abstraction, and specimen collection was completed through the Ohio Perinatal Research Network (OPRN).

Patients with both BPD and PH were identified as those patients with evidence of abnormally elevated pulmonary arterial pressure on echocardiography with a structurally normal heart. Elevated pulmonary arterial pressure on echocardiography was defined by the presence of any of the following four criteria: 1) right ventricular hypertrophy; 2) flattening of the intraventricular septum; 3) tricuspid regurgitation (TR) in the absence of pulmonary stenosis; and/or 4) elevated right ventricular pressure as estimated by TR jet velocity [2, 15- 
17]. Infants with BPD who did not have $\mathrm{PH}$ according to these criteria were considered controls. At the time of this study, there was no screening protocol for $\mathrm{PH}$ in patients with BPD, and therefore $62 \%$ of the control population was screened with echocardiography for $\mathrm{PH}$. Indications for iNO were variable, including support of lung development, as well as severe BPD. Patients with congenital heart disease (except for patent ductus arteriosus and/or atrial septal defect), were excluded. Patients with anatomical causes of PH, including diaphragmatic hernia or other causes of lung hypoplasia were also excluded.

Blood samples were collected from all patients at enrollment. Whole blood samples were immediately centrifuged and the plasma collected and stored at $-80^{\circ} \mathrm{C}$. Concentrations of metabolites (citrulline, arginine, ornithine, and proline) and asymmetric dimethylarginine (ADMA), were determined using reverse-phase high-performance liquid chromatography (HPLC) and expressed in concentration $(\mu \mathrm{M})$ as previously described [9]. Briefly, analysis was performed on a Shimadzu HPLC equipped with a RF-10AXL fluorescence detector and Class VP 7.3 data analysis software. Fluorescence was monitored at an excitation wavelength of $250 \mathrm{~nm}$ and an emission wavelength of $395 \mathrm{~nm}$ [9].

\section{Statistical analyses}

Data are reported as mean $\pm \mathrm{SD}$, or as number and percent. Demographics and clinical characteristics of cases (BPD and PH) and controls (BPD alone) were compared using $\chi^{2}$ test for categorical data and Student $t$-test for continuous data. Blood metabolite levels were compared between study populations by Student $t$-test. A p value of $<0.05$ was considered statistically significant.

\section{Results}

Among 122 patients with BPD enrolled in the study, 23 had both BPD and PH (cases), 95 had BPD alone (controls), and 4 patients met criteria for exclusion. The diagnosis of PH in patients with BPD was made by one of the following predominant findings on echocardiography: right ventricular hypertrophy (39\%), flattening of the intraventricular septum (9\%), tricuspid regurgitation in the absence of pulmonary stenosis (35\%), elevated right ventricular pressure (17\%). There were no differences in clinical characteristics between cases and controls (Table I). These infants were born very preterm and had very low birth weight, and as perhaps expected for an all referral NICU a number of these patients were admitted relatively late in their clinical course. Of the patients with both BPD and $\mathrm{PH}, 65 \%$ were discharged on supplemental oxygen therapy, $22 \%$ of infants were discharged on furosemide, and $13 \%$ of infants received NO therapy during their hospital stay. We found no differences between cases and controls in respiratory treatments after admission to the NICU (Table II).

Plasma samples from 118 patients were analyzed for ADMA, arginine, citrulline, ornithine and proline levels (Table III). The average sample day of life for patients with both BPD and PH was $54 \pm 40$ days, and $38 \pm 22$ days for those with BPD alone. The plasma levels of ADMA were found to be approximately two-fold higher in patients with both BPD and PH than in patients with BPD alone. Plasma levels of citrulline, arginine, ornithine, and proline were not different between patients with both BPD and PH and patients with BPD alone 
(Table III). We found no difference in citrulline-to-ornithine ratio between cases and controls. However, the plasma arginine-to-ADMA ratio was nearly three times lower in patients with both BPD and PH than patients with BPD alone. For plasma ADMA levels drawn prior to 28 days of life ( $\mathrm{n}=27$ ), we found that the mean levels were significantly ( $\mathrm{p}=$ $0.02)$ higher in patients with both BPD and PH $(4.3 \pm 0.9 \mu \mathrm{M})$ than in the 20 patients with $\mathrm{BPD}$ alone (2.6 $\pm 0.3 \mu \mathrm{M}$ BPD). Of the patients with levels measured prior to 28 days, $100 \%$ had echocardiography, and $26 \%$ were diagnosed with $\mathrm{PH}$.

\section{Discussion}

In this study, ADMA levels were increased in patients with BPD-associated PH compared with patients with BPD alone. Higher levels of ADMA in BPD and PH were found in those plasma samples collected before 28 days of life, and arginine-to-ADMA ratio was lower in patients with both BPD and PH than in those with BPD alone. These data provide evidence that ADMA may be a biomarker for the development of PH in patients with BPD.

Elevated ADMA levels are indicative of endothelial dysfunction [18]. Elevated levels of ADMA could be caused by increased synthesis via PRMT and/or proteolysis or by decreased breakdown by DDAH. There are no data relating PRMT or DDAH activity in BPD. In adult congestive heart failure DDAH activity is decreased resulting in elevated ADMA [19]. In neonates, plasma ADMA has been implicated in the control of fetoplacental circulation and circulatory adaptation following birth, and plasma ADMA may be a marker for mortality in necrotizing enterocolitis [20-22]. Clinical risk factors that may predict $\mathrm{PH}$ in patients with BPD include oligohydramnios, chorioamnionitis, fetal growth restriction, longer duration of mechanical ventilation, and increased rates of infection [5, 2327]. Identifying risk factors and/or screening methods for the development of BPDassociated PH may allow for novel interventions to improve morbidity and mortality [28]. Our data are consistent with plasma levels of ADMA being a potential biomarker for the development of PH in patients with BPD.

Given the central role of NO in maintaining a low pulmonary vascular resistance our findings also suggest that ADMA may be involved in the mechanism of increased vascular resistance in patients with BPD who develop PH. The elevated levels of ADMA and the lower arginine-to-ADMA ratios suggest that NOS is more likely to be inhibited in these patients. Therefore, therapeutic approaches aimed at lowering ADMA levels in neonates with BPD may warrant further study.

In addition to NO, superoxide anion is also generated from eNOS when it is uncoupled. The superoxide generated by uncoupled eNOS has been implicated in cardiovascular disease [29]. Therefore, we speculate that with increasing levels of ADMA and arginase in disease processes such as pulmonary hypertension, the NO:superoxide anion ratio would be relatively decreased.

There are several weaknesses of this study, including the small sample size. These data are preliminary and need to be validated in a larger cohort. There was wide variation in the timing of blood draws. This is due in part to the all referral nature of our NICU, where some 
patients with BPD are referred relatively early, and others are referred much later in their course. We had no patients in this cohort admitted on the first day of life. Our method of detection of PH was echocardiography. Heart catheterization continues to be the gold standard for the diagnosis of $\mathrm{PH}$ to accurately characterize the etiology and grade severity, in order to best guide therapy [30]. However, in this highly vulnerable patient population routine catheterization are not practical.

In conclusion, we found that in preterm infants with $\mathrm{BPD}$, those that developed $\mathrm{PH}$ by echocardiographic criteria had higher plasma levels of ADMA and lower plasma arginineto-ADMA ratios than those patients with BPD that did not develop PH. Because ADMA was first described as an endogenous inhibitor of NOS in 1992 and first detected in human plasma in 1997 [21, 31], it has been implicated in multiple disease processes related to endothelial dysfunction [13]. The present findings add to the disease processes that involve alterations in plasma ADMA levels. Current clinical trials involving the L-arginine/NO pathway, such as supplemental oral citrulline for the prevention and treatment of $\mathrm{PH}$ in children, have shown promising results [32]. In the present study, however, we did not find a decrease in citrulline-to-ornithine ratio in patients with both BPD PH. Future multi-center studies are needed to determine more precise metabolite levels in this patient population. Additional studies are also needed to determine if elevated ADMA levels in BPD-associated $\mathrm{PH}$ are due to an increase in ADMA synthesis or a decrease in ADMA catabolism. We speculate that therapies aimed at increasing arginine levels, decreasing ADMA synthesis, and/or increasing ADMA catabolism, have the potential to prevent $\mathrm{PH}$ in preterm infants with BPD.

\section{Acknowledgments}

Funded by the Center for Clinical and Translational Research at The Research Institute at Nationwide Children's Hospital (UL1TR001070).

We thank research staff of the Ohio Perinatal Research Network (OPRN) and the Perinatal Research Repository (PRR) for enrollment and data collection. We appreciate the contributions of Molly Augustine (Nationwide Children's Hospital) for the development of the methods.

\section{Abbreviations}

$\begin{array}{ll}\text { ADMA } & \text { Asymmetric dimethylarginine } \\ \text { BPD } & \text { bronchopulmonary dysplasia } \\ \text { CPAP } & \text { continuous positive airway pressure } \\ \text { HPLC } & \text { high-performance liquid chromatography } \\ \text { NO } & \text { itric oxide } \\ \text { NOS } & \text { nitric oxide synthase } \\ \text { PH } & \text { pulmonary hypertension } \\ \text { SDMA } & \text { symmetric dimethylarginine }\end{array}$




\section{References}

1. Taeusch, HBR.; Gleason, C. Avery's Diseases of the Newborn. 2005. p. 723-45.

2. Slaughter JL, Pakrashi T, Jones DE, South AP, Shah TA. Echocardiographic detection of pulmonary hypertension in extremely low birth weight infants with bronchopulmonary dysplasia requiring prolonged positive pressure ventilation. J Perinatol. 2011; 31:635-40. [PubMed: 21311503]

3. An HS, Bae EJ, Kim GB, Kwon BS, Beak JS, Kim EK, et al. Pulmonary hypertension in preterm infants with bronchopulmonary dysplasia. Korean Circ J. 2010; 40:131-6. [PubMed: 20339498]

4. Berkelhamer SK, Mestan KK, Steinhorn RH. Pulmonary hypertension in bronchopulmonary dysplasia. Semin Perinatol. 2013; 37:124-31. [PubMed: 23582967]

5. Ali Z, Schmidt P, Dodd J, Jeppesen DL. Predictors of bronchopulmonary dysplasia and pulmonary hypertension in newborn children. Danish medical journal. 2013; 60:A4688. [PubMed: 23905570]

6. Khemani E, McElhinney DB, Rhein L, Andrade O, Lacro RV, Thomas KC, et al. Pulmonary artery hypertension in formerly premature infants with bronchopulmonary dysplasia: clinical features and outcomes in the surfactant era. Pediatrics. 2007; 120:1260-9. [PubMed: 18055675]

7. Mourani PM, Abman SH. Pulmonary vascular disease in bronchopulmonary dysplasia: pulmonary hypertension and beyond. Curr Opin Pediatr. 2013; 25:329-37. [PubMed: 23615175]

8. Pearson DL, Dawling S, Walsh WF, Haines JL, Christman BW, Bazyk A, et al. Neonatal pulmonary hypertension--urea-cycle intermediates, nitric oxide production, and carbamoyl-phosphate synthetase function. N Engl J Med. 2001; 344:1832-8. [PubMed: 11407344]

9. Cua CL, Rogers LK, Chicoine LG, Augustine M, Jin Y, Nash PL, et al. Down syndrome patients with pulmonary hypertension have elevated plasma levels of asymmetric dimethylarginine. Eur $\mathbf{J}$ Pediatr. 2011; 170:859-63. [PubMed: 21120524]

10. Warwick G, Thomas PS, Yates DH. Biomarkers in pulmonary hypertension. The European respiratory journal. 2008; 32:503-12. [PubMed: 18669790]

11. Klinger JR, Abman SH, Gladwin MT. Nitric oxide deficiency and endothelial dysfunction in pulmonary arterial hypertension. Am J Respir Crit Care Med. 2013; 188:639-46. [PubMed: 23822809]

12. Bode-Boger SM, Scalera F, Ignarro LJ. The L-arginine paradox: Importance of the L-arginine/ asymmetrical dimethylarginine ratio. Pharmacology \& therapeutics. 2007; 114:295-306. [PubMed: 17482266]

13. Boger RH. Asymmetric dimethylarginine (ADMA) and cardiovascular disease: insights from prospective clinical trials. Vascular medicine. 2005; 10 (Suppl 1):S19-25. [PubMed: 16444865]

14. Jobe AH, Bancalari E. Bronchopulmonary dysplasia. Am J Respir Crit Care Med. 2001; 163:17239. [PubMed: 11401896]

15. Summar ML, Hall L, Christman B, Barr F, Smith H, Kallianpur A, et al. Environmentally determined genetic expression: clinical correlates with molecular variants of carbamyl phosphate synthetase I. Mol Genet Metab. 2004; 81 (Suppl 1):S12-9. [PubMed: 15050969]

16. Janda S, Shahidi N, Gin K, Swiston J. Diagnostic accuracy of echocardiography for pulmonary hypertension: a systematic review and meta-analysis. Heart. 2011; 97:612-22. [PubMed: 21357375]

17. Berger M, Haimowitz A, Van Tosh A, Berdoff RL, Goldberg E. Quantitative assessment of pulmonary hypertension in patients with tricuspid regurgitation using continuous wave Doppler ultrasound. J Am Coll Cardiol. 1985; 6:359-65. [PubMed: 4019921]

18. Boger RH. Asymmetric dimethylarginine (ADMA) modulates endothelial function--therapeutic implications. Vascular medicine. 2003; 8:149-51. [PubMed: 14989553]

19. Visser M, Paulus WJ, Vermeulen MA, Richir MC, Davids M, Wisselink W, et al. The role of asymmetric dimethylarginine and arginine in the failing heart and its vasculature. European journal of heart failure. 2010; 12:1274-81. [PubMed: 20923854]

20. Richir MC, Siroen MP, van Elburg RM, Fetter WP, Quik F, Nijveldt RJ, et al. Low plasma concentrations of arginine and asymmetric dimethylarginine in premature infants with necrotizing enterocolitis. The British journal of nutrition. 2007; 97:906-11. [PubMed: 17381965] 
21. Siroen MP, Teerlink T, Nijveldt RJ, Prins HA, Richir MC, van Leeuwen PA. The clinical significance of asymmetric dimethylarginine. Annual review of nutrition. 2006; 26:203-28.

22. Vida G, Sulyok E, Ertl T, Martens-Lobenhoffer J, Bode-Boger SM. Plasma asymmetric dimethylarginine concentration during the perinatal period. Neonatology. 2007; 92:8-13. [PubMed: 17596731]

23. Kim DH, Kim HS, Choi CW, Kim EK, Kim BI, Choi JH. Risk factors for pulmonary artery hypertension in preterm infants with moderate or severe bronchopulmonary dysplasia. Neonatology. 2012; 101:40-6. [PubMed: 21791938]

24. Waruingi W, Mhanna MJ. Pulmonary hypertension in extremely low birth weight infants: characteristics and outcomes. World journal of pediatrics: WJP. 2014; 10:46-52. [PubMed: 24464663]

25. Check J, Gotteiner N, Liu X, Su E, Porta N, Steinhorn R, et al. Fetal growth restriction and pulmonary hypertension in premature infants with bronchopulmonary dysplasia. J Perinatol. 2013; 33:553-7. [PubMed: 23328924]

26. Bhat R, Salas AA, Foster C, Carlo WA, Ambalavanan N. Prospective analysis of pulmonary hypertension in extremely low birth weight infants. Pediatrics. 2012; 129:e682-9. [PubMed: 22311993]

27. Alfiero Bordigato M, Piva D, Di Gangi IM, Giordano G, Chiandetti L, Filippone M. Asymmetric dimethylarginine in ELBW newborns exposed to chorioamnionitis. Early human development. 2011; 87:143-5. [PubMed: 21138787]

28. Collaco JM, Romer LH, Stuart BD, Coulson JD, Everett AD, Lawson EE, et al. Frontiers in pulmonary hypertension in infants and children with bronchopulmonary dysplasia. Pediatr Pulmonol. 2012; 47:1042-53. [PubMed: 22777709]

29. Lei H, Luo S, Qin H, Xia Y. Molecular Mechanisms of Endothelial NO Synthase Uncoupling. Current pharmaceutical design. 2013

30. Mourani PM, Sontag MK, Younoszai A, Ivy DD, Abman SH. Clinical utility of echocardiography for the diagnosis and management of pulmonary vascular disease in young children with chronic lung disease. Pediatrics. 2008; 121:317-25. [PubMed: 18245423]

31. Chen BM, Xia LW, Zhao RQ. Determination of N(G),N(G)-dimethylarginine in human plasma by high-performance liquid chromatography. Journal of chromatography B, Biomedical sciences and applications. 1997; 692:467-71.

32. Barr FE, Macrae D. Inhaled nitric oxide and related therapies. Pediatr Crit Care Med. 2010; 11:S30-6. [PubMed: 20216160] 


\section{Table 1}

Demographic and clinical characteristics

\begin{tabular}{|c|c|c|c|}
\hline & BPD alone $(N=95)$ & BPD + PH $(N=23)$ & p-value \\
\hline Gestational age (wks) & $28.2 \pm 3.7$ & $27.5 \pm 3.9$ & 0.42 \\
\hline Birth weight (g) & $1179 \pm 597$ & $959 \pm 517$ & 0.09 \\
\hline Female, $n(\%)$ & $31(33)$ & $8(35)$ & 0.84 \\
\hline Caucasian, $n(\%)$ & $68(72)$ & $18(78)$ & 0.41 \\
\hline Birth Head Circ (cm) & $26 \pm 4$ & $24 \pm 3$ & 0.07 \\
\hline 5 min APGAR & $6 \pm 2$ & $6 \pm 2$ & 0.35 \\
\hline Admission age (days) & $28 \pm 48$ & $46 \pm 88$ & 0.36 \\
\hline PDA, n (\%) & $41(43)$ & $9(39)$ & 0.85 \\
\hline $\mathrm{IVH}, \mathrm{n}(\%)$ & $20(21)$ & $8(35)$ & 0.17 \\
\hline Hydrocephalus, n (\%) & $2(2)$ & $1(4)$ & 0.54 \\
\hline NEC, n (\%) & $4(4)$ & $1(4)$ & 0.98 \\
\hline ROP, n (\%) & $11(12)$ & $2(9)$ & 0.69 \\
\hline Pneumothorax, n (\%) & $2(2)$ & $2(9)$ & 0.13 \\
\hline Nitric Oxide, n (\%) & $7(7)$ & $3(13)$ & 0.40 \\
\hline Post-admission, steroids, n (\%) & $31(33)$ & $11(48)$ & 0.17 \\
\hline Caffeine, n (\%) & $57(60)$ & $15(65)$ & 0.65 \\
\hline Surfactant, n (\%) & $61(64)$ & $15(65)$ & 0.73 \\
\hline Discharge weight (g) & $3433 \pm 1278$ & $3677 \pm 1351$ & 0.44 \\
\hline
\end{tabular}

Abbreviations: BPD, bronchopulmonary dysplasia; $\mathrm{PH}$, pulmonary hypertension; PDA, patent ductus arteriosus; IVH, intraventricular hemorrhage; NEC, necrotizing enterocolitis; ROP, retinopathy of prematurity. 


\section{Table 2}

Respiratory treatments after admission

\begin{tabular}{lccc}
\hline & BPD alone $(\boldsymbol{N = 9 5})$ & BPD + PH $(\boldsymbol{N = 2 3 )}$ & p-value \\
\cline { 1 - 1 } NC < 1 LPM, n (\%) & $63(66)$ & $18(78)$ & 0.33 \\
NC at 1-1.99 LPM, n (\%) & $32(34)$ & $11(48)$ & 0.23 \\
NC 22 LPM, n (\%) & $17(18)$ & $4(17)$ & 0.92 \\
Nasal CPAP, n (\%) & $52(55)$ & $17(74)$ & 0.09 \\
Conventional vent, n (\%) & $52(55)$ & $15(65)$ & 0.42 \\
HFOV, n (\%) & $3(3)$ & $1(4)$ & 0.79 \\
HFJV, n (\%) & $2(2)$ & $0(0)$ & 0.48 \\
Ventilation days & $25 \pm 31$ & $31 \pm 39$ & 0.58 \\
Oxygen at discharge, n (\%) & $43(45)$ & $13(57)$ & 0.32 \\
\hline
\end{tabular}

Abbreviations: BPD, Bronchopulmonary Dysplasia; PH, Pulmonary Hypertension; NC, Nasal Cannula; LPM, liters per minute; CPAP, Continuous Positive Pressure Ventilation; HFOV, High Frequency Oscillatory Ventilation; HFJV, High Frequency Jet Ventilation. 


\section{Table 3}

L-arginine/NO pathway Metabolites

\begin{tabular}{lccc}
\hline Metabolites & BPD alone $(\boldsymbol{N = 9 5})$ & BPD + PH $(\boldsymbol{N = 2 3})$ & p-value \\
Arginine & $201.0 \pm 79.9$ & $228.7 \pm 84.8$ & 0.32 \\
Ornithine & $88.5 \pm 36.6$ & $96.7 \pm 33.9$ & 0.46 \\
Proline & $260.2 \pm 98.9$ & $245.4 \pm 88.8$ & 0.62 \\
Citrulline & $15.9 \pm 9.8$ & $18.6 \pm 11.0$ & 0.45 \\
ADMA & $2.2 \pm 2.8$ & $5.0 \pm 4.0$ & 0.04 \\
Arginine/ADMA & $329.8 \pm 561.6$ & $131.1 \pm 151.5$ & 0.03 \\
Arginine/Ornithine & $2.4 \pm 0.8$ & $2.5 \pm 1.1$ & 0.75 \\
\hline
\end{tabular}

Abbreviations: NMMA, $\mathrm{N}^{\omega}$-monomethylarginine; ADMA, asymmetric dimethylarginine; SDMA, symmetric dimethylarginine.

* All concentrations reported as mean $\pm \mathrm{SD}$, and in $\mu \mathrm{M}$ concentrations. 